\title{
Feeding Frequency and its Related Effect on Productivity and Survival Rate of Glossina Pallidipes in Kality Tsetse Mass Rearing and Production Center for the Purpose of Sterile Insect Technique (SIT)
}

\author{
Mintesnot Tsegaye, Behablom Meharenet*, Tekaligni Desta, Bekele Lema, Tazezew Desalegn \\ and Dessalew Shitu \\ National Institute for Control and Eradication of Tsetse Fly and Trypanosomosis, Ministry of Livestock \& Fisheries, Kaliti \\ Tsetse flies Mass Rearing and Irradiation Center, Ethiopia
}

*Corresponding author: Behablom Meharent, National Institute for Control and Eradication of Tsetse Fly and Trypanosomosis, Ministry of Livestock \& Fisheries, Kaliti Tsetse flies Mass Rearing and Irradiation Center, Ethiopia

\section{ARTICLE INFO}

Received: May 22, 2020

Published: 幽 June 05, 2020

Citation: Mintesnot T, Behablom M, Tekaligni D, Bekele L, Tazezew D, Dessalew S. Feeding Frequency and its Related Effect on Productivity and Survival Rate of Glossina Pallidipes in Kality Tsetse Mass Rearing and Production Center for the Purpose of Sterile Insect Technique (SIT). Biomed J Sci \& Tech Res 28(1)-2020. BJSTR. MS.ID.004604.

Keywords: Blood Feeding Frequency; Mortality Rate; Fecundity; Pupae Per Initial Female (PPIF); Glossina Pallidipes
ABSTRACT

Background \& Objectives: The Sterile Insect Technique (SIT) is non - intrusive to the environment which entails the release of sterile male flies obtained by mass rearing and this depends on the availability of a suitable blood diet for the flies. Therefore, qualitative and quantitative amount of blood is needed for the maintenance of fly colonies in vitro. However, in a mass-rearing facility, the logistics of obtaining sterile, high-quality blood remains problematic. So, appropriate and economical use of blood in the membrane (in vitro) feeding technique provides a means to produce tsetse flies more economically and with less risk but this has not been established for G. Pallidipes in Ethiopia. Therefore, this study aimed to establish the optimum feeding frequency and regime required for tsetse colonies of G.pallidipes in Ethiopia.

Methods: To optimize the weekly feeding operation (duration of feeding and frequency of feeding) for G. pallidipes, two different combinations of feeding frequency were tested using defibrinated gamma-irradiated bovine blood. Two groups of experimental flies G. pallidipes each had 720 (580 female and 140 male) newly emerged flies were randomly allocated to two groups to be subjected to different feeding regimes for a period of 90 days. Each group has six replication of cage each constituted 60 flies (48 female and 12 male). One group was fed three times per week on days 1, 3 and 5 and the second group was fed five times on days per week $1,2,4,5$ and 7 . These two regimes were chosen because the first one has been used as a feeding option in the facility (control), while the second one reveals what reproductive performance a tsetse can achieve on the highest possible feeding regime. Pupae were collected daily and mortality checks were done every week. The weekly datasets of the G.pallidpes colonies, in different feeding regimes, were measured by observation of tsetse production parameters including survival, pupae production, and size.

Results: The survival rate of flies fed three times a week was lower when compared with flies fed five times a week. Also Flies fed five times a week had a significantly higher number of pupae production when compared to the production in other. Likewise, a significantly higher mean fecundity was recorded among flies fed five times a week compared with flies fed three times a week. Flies fed three times a week had more of small pupae (class A \& B) compared to flies fed five times a week.

Interpretation \& Conclusion: Based on the laboratory results, five laboratorysized meals may be sufficient to meet the energy demands of normal larval development in the laboratory and increased their productivity compared to the three-sized meal. 


\section{Background}

Tsetse flies are the sole vectors of Human and Animal African Trypanosomiasis (HAT) in sub-Saharan Africa and are efficient vectors of African trypanosomes, causative agents of sleeping sickness in humans and nagana in domesticated animals [1,2]. The influence of tsetse on African agriculture through the transmission of trypanosomosis continues to be a major constraint to the development of national economies and their achievement of selfsufficiency in basic food production. It is also one of the major impediments to livestock development and agricultural production in Ethiopia contributing negatively to the overall development in general and food self-reliance efforts of the nation in particular. While tsetse-borne trypanosomosis is excluding some 180,000 $200,000 \mathrm{~km}^{2}$ of agriculturally suitable land in the west and southwest of the country, 14 million head of cattle, an equivalent number of small ruminants, nearly 7 million equines and 1.8 million camels are at the risk of contracting trypanosomosis at any time $[3,4]$.

There are different methods developed for tsetse and trypanosomiasis control or eradication but all have their specific advantages and limitations. The currently available and environmentally acceptable methods include parasite control by trypanocides, vector intervention using traps and insecticidetreated devices and special formulations of insecticides on livestock. Others are entomological and intend to disrupt the transmission cycle by reducing the number of tsetse flies. These include Sequential Aerosol Technique (SAT) and the Sterile Insect Technique (SIT). A combination of several of the above methods could be used as part of an Area-wide Integrated Pest Management [5]. Recently, the application of the SIT was demonstrated by the area-wide eradication of Glossina austeni Newstead in Unguja Island, Zanzibar [6,7]. As a consequence of this success, programs were developed to apply this approach on the African mainland and, in 1996, the government of Ethiopia embarked on such a program to create a zone free of Glossina pallidipes in the Southern Rift Valley of Ethiopia and established Kality tsetse mass rearing and irradiation center in august 2000 to create a zone free of Glossina pallidipes in the Southern Rift Valley of Ethiopia. The facility has a colony capacity of approximately 7 million female flies and will be able to produce over 700000 sterile male flies per week enough to treat approximately $7000 \mathrm{~km}^{2}$ at a time [8]. However, the major constraint in these early programs has been the large scale production of sufficient sterile male flies for release. The establishment and expansion of $G$. pallidipes colonies for mass production of sterile male flies proved to be difficult and they collapsed several times due to the deleterious effect of lack of quality blood and good feeding management, high infection rates with the salivary gland hypertrophy virus, unsuitable environmental factors even if it requires the mass production of males for sustainable sequential release until major population reductions are achieved [9-13].
Tsetse rearing evolved from feeding on live hosts to an in vitro rearing system where blood is fed to flies through a silicone membrane [13]. Both males and females feed on blood. The female reproduces by adenotrophic viviparity, one larva at a time being nourished in utero by a secretion from the uterine gland [14]. This is very important since both males and females (also including the larvae within the uterus) depend on the blood for their survival and nourishment. The amount of blood imbibed during the interlarval period is the major factor determining the productivity and survival rate of tsetse, Glossina species. Therefore, qualitative and quantitative amount of blood is needed for the maintenance of fly colonies [15] in vitro. In vitro feeding system is recommended if a reliable source of quality tested blood is available [16-18]. However, in a mass-rearing facility, the logistics of obtaining sterile, highquality blood remains problematic. So, appropriate and economical use of blood in the membrane (in vitro) feeding technique provides a means to produce tsetse flies more economically and with less risk but this has not been established for G. Pallidipes in Ethiopia. Therefore, the objective of this study was to establish the optimum feeding frequency and regime required for tsetse mass rearing and production colonies of G.pallidipes.

\section{Material and Methods}

\section{Study Area}

The present experimental study was conducted at Kality Tsetse Fly Mass Rearing and Irradiation Center within the capital, Addis Ababa Region. Addis Ababa is the capital city of Ethiopia with geographical locations $9.03^{\circ}$ North; $38.74^{\circ}$ East, latitude and longitude, respectively. The Kality tsetse mass rearing and irradiation Centre was initiated in August 2000 with the mission of creating a zone free of Glossina pallidipes in the Southern Rift Valley of Ethiopia. The facility has a colony capacity of approximately 7 million female flies and will be able to produce over 700000 sterile male flies per week enough to treat approximately $7000 \mathrm{~km}^{2}$ at a time [12]. The insectary has its microenvironment adjusted as the need of the G. pallidipes production. The experimental flies were maintained in the controlled and optimum environmental conditions of insectarium similar to the general colony of the center at a temperature of $23-25{ }^{\circ} \mathrm{C}$ and an $\mathrm{RH}$ of $75-80 \%$ [19]. Moreover, the experiments were conducted based on the center's standard operating procedure for irradiation and tsetse mass rearing and production

\section{Study Period and Population}

The study was conducted from March 25 to June 20, 2019, and included 720 G.pallidipes (576 females and 144males) to assess the effect of feeding frequency on the productivity and survival rate of $G$. pallidipes adult flies in colony cages maintained and reared under manual in-vitro feeding of defibrinated bovine blood under laboratory conditions. All pupae, teneral and adult flies (G. pallidipes) of both sexes were used for the experiments and were derived randomly from Kality tsetse fly mass rearing and 
irradiation center from the stock colonies of $G$. pallidipes. The adult flies used in the study were obtained from the same production batch of pupae originated from the main colonies in the insectary and After emergence, flies were sex-sorted and placed separately in colony cages following predefined sex ratios (1:4) (48 females per 12 males) in per cage within the rearing section (room) as the main colony.

\section{Study Design}

Feeding Frequency Test: Two experimental groups were established and reared based on feeding frequency regimes as the feeding of three and five times a week. Each group has six replicates of a cage with 48 female and 12 male flies per cage called colonies using zero-day mating immediately after they had emerged from incubated pupae using a cooler (chiller) set at $+40 \mathrm{C}$ and were maintained in a replicated cages diameter of $20 \mathrm{~cm}$ and width of $5 \mathrm{~cm}$ netting on top and bottom for feeding and collection of the hatched larvae [19]. All twelve established colonies were again allocated into two groups (six colonies in each group) to be subjected to different feeding regimes during the subsequent pregnancy cycle for three consecutive months. One group was fed three times per week on $1^{\text {st }}, 3^{\text {rd }}$ and $5^{\text {th }}$ and the second group was fed five times on $1^{\text {st }}, 2^{\text {nd }}, 4^{\text {th }}, 5^{\text {th }}$ and $7^{\text {th }}$ days per week.

These two feeding regimes were selected based on the former one has been used as a feeding option in the facility, while the second one revealed what reproductive performance a tsetse fly can achieve on the highest possible feeding regime. Pupae were collected daily and mortality checks were done every week. The weekly datasets of the G.pallidpes colonies, in different feeding regimes, were measured by observation of tsetse production parameters including fecundity, Pupae Per Initial Female (PPIF), mortality rate and pupae production and pupal size class graded based on their size. Both experimental groups of Flies were fed from a similar quality of blood factor from the same batch of defibrinated gammairradiated bovine blood meal using an in vitro silicon membrane system which was previously collected aseptically and frozen at $-20{ }^{\circ} \mathrm{C}[12,20]$. The feeding system was installed in a climatic room that was maintained a similar environmental condition of $25 \pm 1{ }^{\circ} \mathrm{C}$ and $50 \pm 5 \%$ humidity for all treatments. The flies remained in the feeding room for less than 30 minutes based on [21,22] and placed under similar and optimum environmental conditions. The holding room temperature and humidity was adjusted (controlled) and monitored daily from the data logger set in the rearing room. The only difference between treatments was the feeding frequency of three times a week (Monday, Wednesday and Friday) and five times a week (Monday, Tuesday, Thursday, Friday and Sunday).

\section{Productivity Testss}

Fecundity Test: Mating cages were placed in individual larvipositioned cups and Pupae were collected from all cages daily in the morning beginning from days 16 up to the end of the experiment. All data were recorded separately per tested groups per cage and analyzed for three continuative months including their pupal size which was graded as indicated in Annex 5 [16]. Fecundity was expressed as the number of pupae produced per initial female and pupae produced per 10 days, by considering day 16 after immediately they emerged from pupae stage as the first larviposition day. Mortality of female flies was first measured in the third week after emergence and five more times in their life span thereafter. The average productivity, measured as the number of Pupae Per Initial Female (PPIF), survival rate (mortality) and the number of pupae production, were measured and analyzed about tested groups.

Pupae Sorting and Grading Test: The size of pupae was measured by using a mechanical pupae sorter machine that separates the pupae based on their diameter. The sorter consists of a pair of inclined counter-rotating set to diverge by a defined size and weight. Pupae are fed on the top of the roller at the narrower end and fall into the collecting container when they have traveled along with the roller to the point when their diameter matches roller spacing. The standard system has five collecting shuts labeled A (smallest) to E (largest); the length of the collection area has been adjusted to correspond the five weight classes previously has been defined to tsetse pupae of G.pallidipes [16].

Mortality Test: Mortality was recorded daily (except on Saturdays and Sundays) for each test group until the death of the last individual. Dead flies were sorted into blood-fed and starved fly mortalities [16].

Data Analysis: To optimize the weekly feeding operation (duration of feeding and frequency of feeding) for G. pallidipes, two different combinations of feeding frequency were tested using defibrinated gamma-irradiated bovine blood. For both groups, the two feeding tests were continued for 17 weeks. All statistical analysis was performed using STATA software version 12 (Stata Corp, Texas, USA) [23]. Pair-wise comparisons of median survival between test groups were estimated using a Tukey'spost-hoc test ('glht' function in the 'multcomp'package). Feeding frequency was used as explanatory variables and survival rate as the response variable. The pupal production and the mean of pupal size were analyzed using general linear models [21]. The smallest AICc of different models was used to choose the best model and the significance of fixed effect was tested using the likelihood ratio test. Pair-wise comparisons of median fecundity between treatments were tested with a Tukey'spost-hoc test ('glht'function in the 'multcomp'package). Female productivity was estimated as pupae per initial female (PPIF, the total number of pupae produced in a given time divided by the number of initial females). The unit 'PPIF' is commonly used to assess the health of the Glossina colonies. Female productivity was measured as pupae per initial female (PPIF, the total number of pupae produced in a given time divided by the number of initial females). 


\section{Results}

\section{Pupae Per Initial Female and Fecundity}

To optimize the weekly feeding operation for $G$. pallidipes tsetse flies and maximize their production in the facility, two different combinations of feeding frequencies were tested (three times a week and five times a week). For both test groups, the two feeding treatments were continued for 17 weeks. A 10-week comparison of flies maintained and reared fewer than two feeding frequency with the standard round cage with 48 females and 12 males showed that productivity was varied greatly between the two test groups. The overall commutative Pupae Per Initial Female (PPIF) and standard deviation of flies subjected to different feeding regime of five and three times per week were found to be $3.05 \pm 0.47$, and $2.21 \pm 0.4$ respectively both starting from their first lariviposition date which was 16 days later respectively (Figure 1 and table 1). (Figure 1) G. pallidipes cumulative average Pupae Per Initial Female (PPIF) based on both feeding frequency test groups Flies feed five times per week (mean=15.5) were produced significantly more pupae than those fed three times per week (mean=10.8) Tukey HSD, $\mathrm{P}<0.011$ ) $(\mathrm{t}=2.3)$. Similarly statistically significantly higher mean fecundity was recorded among flies fed five times per week (mean=0.059) when compared with flies fed three times per week (mean=0.044) Tukey HSD, $\mathrm{P}<0.037)$ ) ( $\mathrm{t}=2.2$ ) (Figures $2 \& 3$, Table 1). A more detailed analysis (Chi-square test) was done to determine the differences among the proportions of surviving flies (Table 1). The probability that the proportions are different at the $\mathrm{P}<0.05\left(^{*}\right)$ or $\mathrm{P}<0.0001{ }^{(* *}$ ) levels of probability, or not significantly different (n's.), the degrees of freedom for error (df) and the Chi-square (x2) values are indicated. Table 1- levels of significant differences among proportions of surviving, average pupae production and fecundity G. pallidipes flies under feeding frequency tests analyzed using multi linear regression and Tukey mean. (Figure 2) Average Fecundity compared under both feeding frequency test regimes

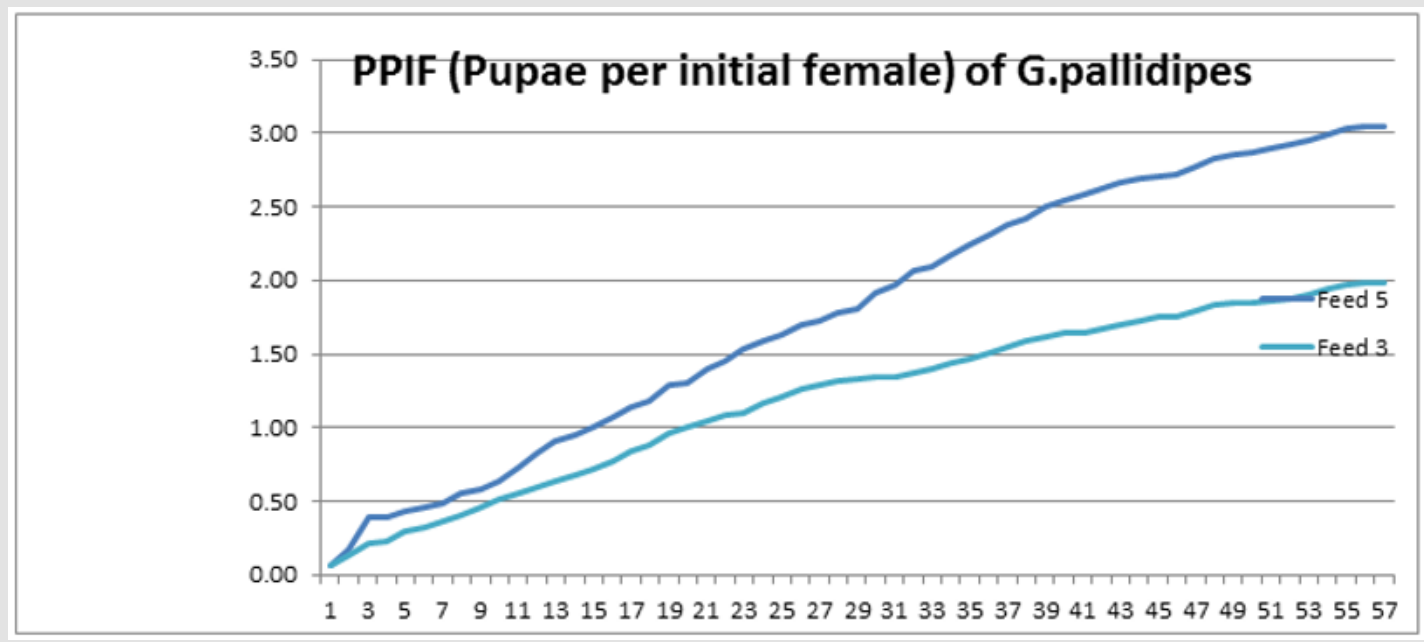

Figure 1: G. pallidipes cumulative average pupae per initial female (PPIF) based on both feeding frequency test groups.

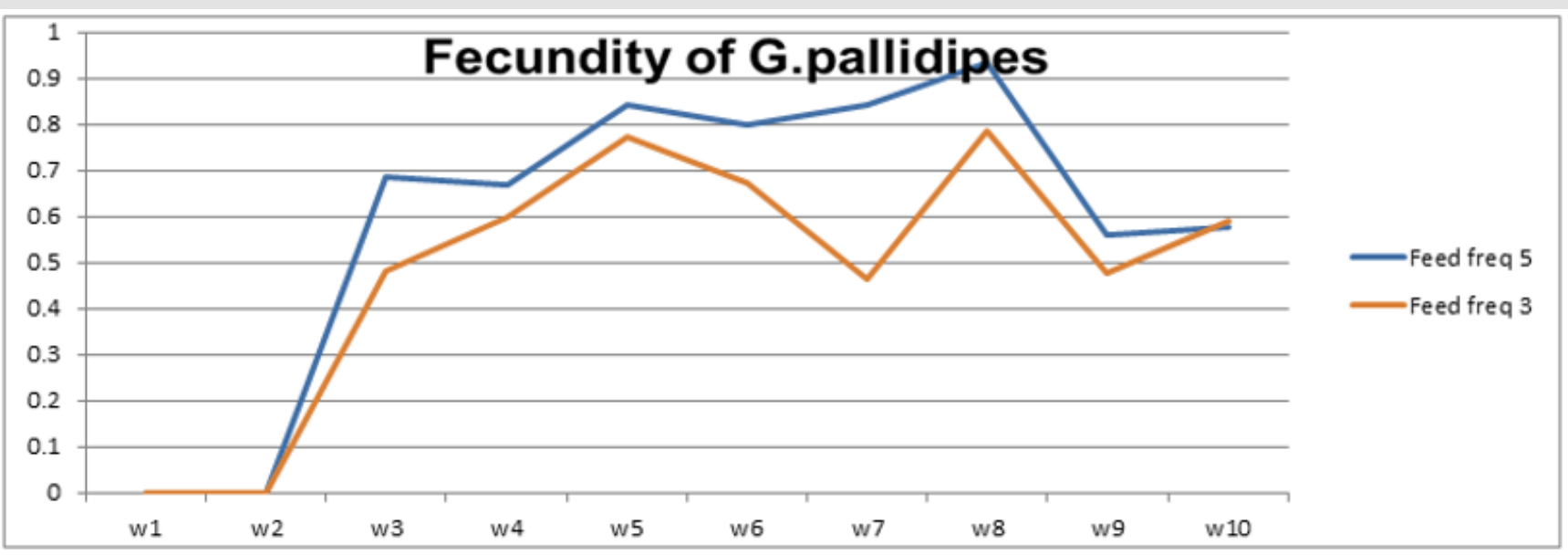

Figure 2: Average Fecundity (pupae per 48 flies/10 days compared under two feeding test regimes. 
Table 1: levels of significant differences among proportions of surviving, average pupae production and fecundity G. pallidipes flies under feeding frequency tests analyzed using multi linear regression and Tukey mean.

\begin{tabular}{|c|c|c|c|c|}
\hline Variable & Contrast & Std. Err. & $t(P>t)$ & [95\% Conf. Interval] \\
\hline \multicolumn{5}{|c|}{ Fecundity } \\
\hline $\begin{array}{l}\text { Three times feeding per } \\
\text { week }\end{array}$ & 0.44 & 0.03 & & $(0.37,0.51)$ \\
\hline Five times feeding per week & 0.59 & 0.06 & & $(0.47,0.702)$ \\
\hline Five vs. three times a week & 0.15 & 0.07 & $2.17(0.032)$ & $(0.01,0.278)$ \\
\hline \multicolumn{5}{|c|}{ Average Pupae } \\
\hline $\begin{array}{l}\text { Three times feeding per } \\
\text { week }\end{array}$ & 10.8 & 0.92 & & $(8.98,12.62)$ \\
\hline Five times feeding per week & 15.53 & 1.6 & & $(12.37,18.69)$ \\
\hline Five vs. three times a week & 4.73 & 1.84 & $2.57(0.011)$ & $(1.09,8.38)$ \\
\hline \multicolumn{5}{|c|}{ Daily Mortality rate } \\
\hline $\begin{array}{l}\text { Three times feeding per } \\
\text { week }\end{array}$ & 0.01 & 0 & & $(0.01,0.017)$ \\
\hline Five times feeding per week & 0.01 & 0 & & $(0.00,0.013)$ \\
\hline $\begin{array}{l}\text { Five vs. three times feeding } \\
\text { regime per week }\end{array}$ & -0.01 & 0 & $(-) 2.03(0.045)$ & $(-0.01,-0.0001)$ \\
\hline
\end{tabular}

\section{Pupae Size Determination}

The pupal size categories for G. pallidipes pupae produced under two feeding frequency five vs. three times per week are given in Figure 6. The results were estimated as a percentage of the total pupae in size categories A-E. Pupae classes represented by letters $\mathrm{A}$ to $\mathrm{E}$ indicated size in ascending order where A refers to small pupae while E refers to large pupae. (Figure 6) Overall Percentage of $G$. pallidipes pupae in different size categories (A-E) between test groups. (Table 2) Levels of significant differences among proportions of pupae size of $G$. pallidipes flies between tested feeding frequencies analyzed using multi linear regression. (Figure 7) Overall Percentage of G. pallidipes pupae in various size (Grade) categories (A-E) between tested feeding frequencies.

Table 2: Levels of significant differences among proportions of pupae size of G. pallidipes flies between tested feeding frequencies analyzed using multi linear regression.

\begin{tabular}{|c|c|c|c|c|c|c|c|c|c|c|}
\hline & Coef. & Std. Err. & $\mathbf{t}$ & $P>t$ & [95\% Conf. & Interval] & RMSE & "R-sq" & $\mathbf{F}$ & $\mathbf{P}$ \\
\hline Pupae Grade A & & & & & & & 0.61 & 0.19 & 4.48 & $0.02^{* *}$ \\
\hline Week number & 0.1 & 0.03 & 3 & $0.01^{* *}$ & 0.03 & 0.17 & & & & \\
\hline Feeding frequency & 0.03 & 0.11 & 0.3 & 0.77 & -0.19 & 0.26 & & & & \\
\hline _cons & -0.32 & 0.44 & -0.7 & 0.48 & -1.21 & 0.58 & & & & \\
\hline Pupae Grade B & & & & & & & 1.65 & 0.1 & 2.12 & 0.13 \\
\hline Week number & 0.18 & 0.09 & 2 & $0.05^{*}$ & 0 & 0.37 & & & & \\
\hline Feeding frequency & -0.12 & 0.3 & -0.4 & 0.7 & -0.73 & 0.49 & & & & \\
\hline _cons & 0.88 & 1.19 & 0.7 & 0.47 & -1.54 & 3.29 & & & & \\
\hline Pupae Grade C & & & & & & & 9.66 & 0.05 & 0.97 & 0.39 \\
\hline Week number & 0.61 & 0.53 & 1.2 & 0.26 & -0.47 & 1.69 & & & & \\
\hline Feeding frequency & -1.38 & 1.76 & -0.8 & 0.44 & -4.96 & 2.19 & & & & \\
\hline _cons & 13.16 & 7 & 1.9 & 0.07 & -1.02 & 27.34 & & & & \\
\hline Pupae Grade D & & & & & & & 12.38 & 0.15 & 3.33 & $0.05^{*}$ \\
\hline Week number & 0.29 & 0.68 & 0.4 & 0.67 & -1.09 & 1.67 & & & & \\
\hline Feeding frequency & 5.75 & 2.26 & 2.5 & $0.02^{* *}$ & 1.17 & 10.33 & & & & \\
\hline _cons & -6.86 & 8.97 & -0.8 & 0.45 & -25.04 & 11.32 & & & & \\
\hline Pupae Grade E & & & & & & & 2.31 & 0.06 & 1.2 & 0.31 \\
\hline Week number & 0.02 & 0.13 & 0.2 & 0.88 & -0.24 & 0.28 & & & & \\
\hline Feeding frequency & 0.65 & 0.42 & 1.5 & 0.13 & -0.2 & 1.5 & & & & \\
\hline _cons & -0.96 & 1.67 & -0.6 & 0.57 & -4.35 & 2.43 & & & & \\
\hline Soft pupae & & & & & & & 0.27 & 0.01 & 0.18 & 0.83 \\
\hline
\end{tabular}




\begin{tabular}{|c|c|c|c|c|c|c|c|c|c|}
\hline Week number & -0.01 & 0.02 & -0.5 & 0.62 & -0.04 & 0.02 & & & \\
\hline Feeding frequency & 0.02 & 0.05 & 0.3 & 0.74 & -0.08 & 0.12 & & & \\
\hline _cons & 0.06 & 0.2 & 0.3 & 0.77 & -0.34 & 0.46 & & & \\
\hline
\end{tabular}

\section{Mortality Rate}

\section{Accumulated and Daily Mortality Rate of G.pallidipes}

The highest overall commutative mortality was recorded in flies fed three times per week (54\%) compared to flies fed five times per week (47\%) over 10 weeks (Figure 4). The lowest daily mean mortality rate was also recorded on flies fed five times per week $(0.6 \%)$ compered to three times per week (1.4\%) (Figure 5). The mean daily survival rate of the female G.pallidipes was significantly varied with the frequency of feeding regime of blood supplied per week $(\mathrm{t}=-2.03 \mathrm{P}=0.045)$ 3.2. Effect of feeding frequency on pupae quality. (Figure 4) Accumulated percentage of dead females G.pallidipes subjected to both feeding regimes. (Figure 5) Percentage of Mean daily mortality of females G.pallidipes subjected to both feeding regimes.

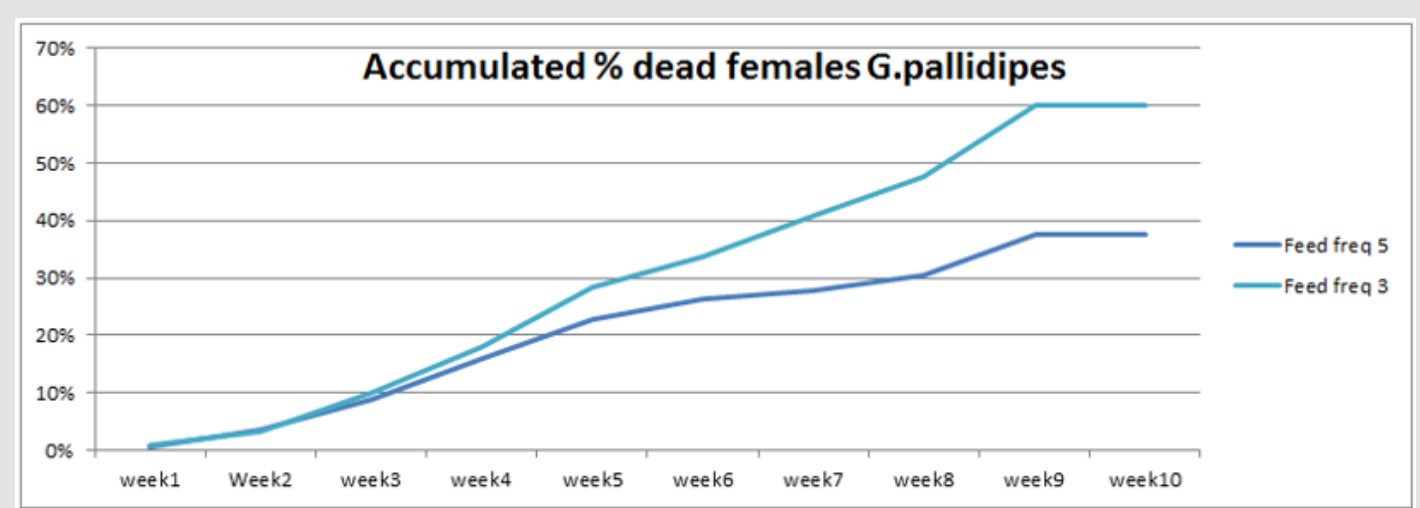

Figure 4: Accumulated percent \% dead females G.pallidipes subjected to different to feeding regime.

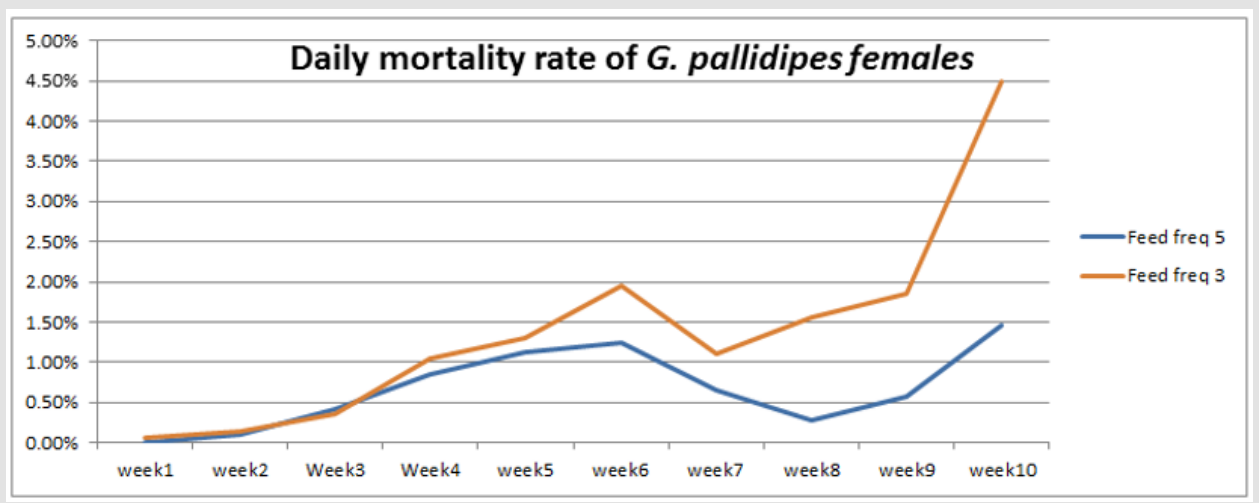

Figure 5: Percentage of Mean daily mortality of females G.pallidipes subjected to different to feeding regime.
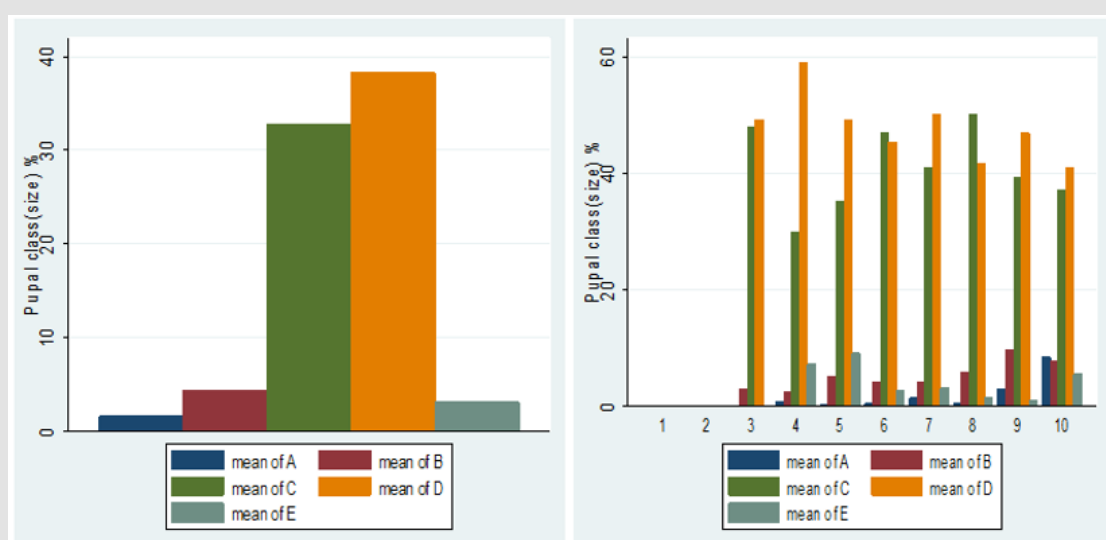

Figure 6: Over all Percentage of G. pallidipes pupae in different size categories (A-E) between test groups. 


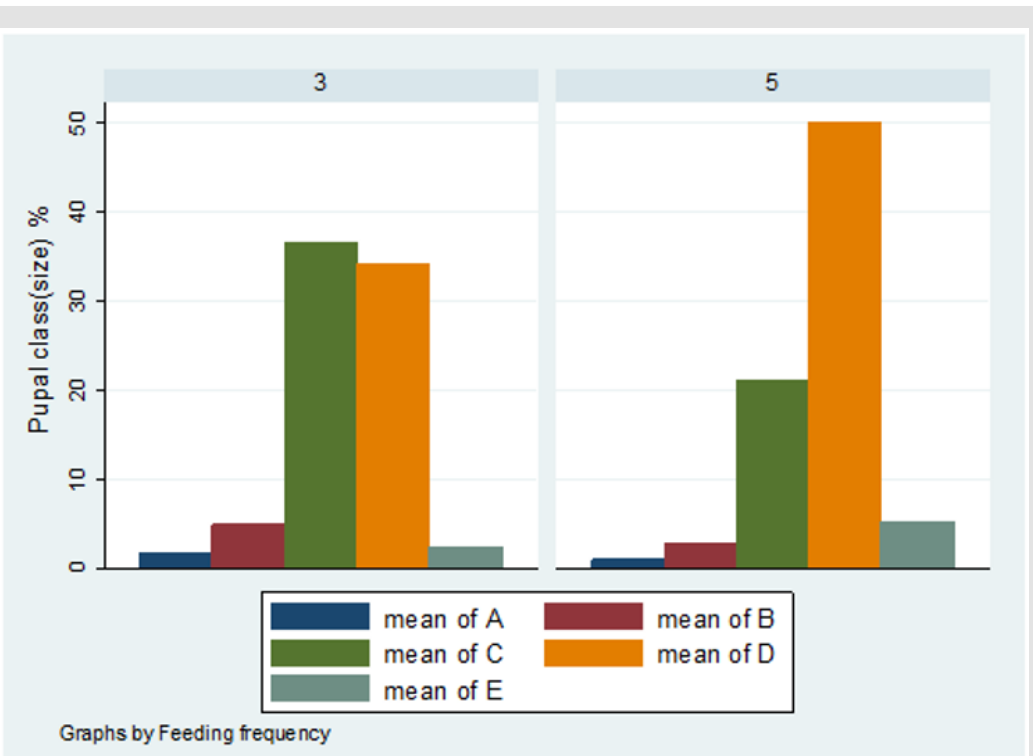

Figure 7: Over all Percentage of G. pallidipes pupae in various size (Grade) categories (A-E) between tested feeding frequencies.

\section{Discussion}

Batches of teneral male and female flies mated on zero days were divided into two groups. The first and the second group was maintained in vitro by feeding flies on defibrinated bovine blood through membranes (three times per week) and five times per week respectively. The results of the present study revealed that feeding frequency had a detrimental effect on the female productivity and mortality rate of G.pallidipes in the laboratory. The overall commutative Pupae Per Initial Female (PPIF) was higher in the group of flies subjected to a feeding regime of five times per week than three times per week. The mean and standard deviation value of flies fed bovine defibrinated blood with the frequency of five times per week and three times per week were found to be $3.05 \pm 0.47$ and $2.21 \pm 0.4$ over 10 weeks respectively. Flies fed five times per week were also produced significantly more pupae (mean=15.5) than those fed three times per week (mean=10.8) Tukey HSD, $\mathrm{P}<0.011)(\mathrm{t}=2.3)$. Likewise, during the production weeks, the fecundity of female $G$. pallidipes as expressed in pupae per female per 10 days (P/F/10 days) was near to above average fecundity required for maintenance of a given colony in flies fed five times per week. On the other hand, below-average mean fecundity was recorded in flies fed three times per week. Statically significantly higher mean fecundity was recorded among flies fed five times per week (mean=0.059) compared with flies fed three times per week (mean=0.044).

Similar findings reported in other glosina species, Glossina palpalis gambiensis Vanderplank and Glossina tachinoids Westwood tolerated a reduction from six to only four days per week. Even without ATP, blood that had been frozen enabled tsetse flies to achieve a high level of productivity. However, Glossina morsitans submorsitans Newstead easily tolerated a reduction from six to three days per week (Monday, Wednesday, and Friday) without reducing female productivity. According to the findings of $[24,25,26]$, the amount of blood imbibed during the interlarval period is the major factor determining the reproductive performance of tsetse, Glossina spp., whether measured as the size or number of pupae produced. There was equally and well-established fact that in the laboratory it is necessary to allow tsetse colonies the opportunity to feed at least every other day to ensure the regular production of pupae [25,7] although when offered a meal every 1 or 2 days not all flies choose to feed at every opportunity, giving a mean feeding interval in the laboratory of between 2 and 2.5 days $[27,28]$. However, this result is different from previous experiments showing that $G$. brevipalpis colony flies be fed for $5 \mathrm{~min}$ three times per week was the most practical and economical solution concerning available labor and volume of blood used [29]. These facts reflect the importance of storing up nutrients ingested early in pregnancy for later use in larval development, for which meals on days 1, 4 and 7 are apparently insufficient in the laboratory. A meal taken only on day 1 is sufficient for normal development up to day 5 , but cannot meet the demands of rapid larval growth from day 6 onwards. In the laboratory female flies which take a full blood meal every third day produce fewer, smaller pupae than those which take on average rather smaller blood meals every second day, and show at what stage in the pregnancy cycle larval development is adversely affected by a nutritional shortfall. Although a reduction in feeding frequency from four to three times per pregnancy cycle resulted in a few abortions apparent from day 6 onwards [22,3032]. However, the PPIF required for the establishment of a colony should be $\geq 3$, and thus the values obtained for feeding frequency of three times per week colonies were usually rather low [29].

Similarly, the highest overall commutative mortality was also recorded in flies fed three times per week (54\%) compared to flies fed five times per week (47\%) over 10 weeks. The lowest daily 
mean mortality rate was also recorded on flies fed five times per week $(0.6 \%)$ compared to three times per week (1.4\%). The mean daily survival rate of the female G.pallidipes was significantly varied with the frequency of feeding regime of blood supplied per week $(\mathrm{t}=-2.03 \mathrm{P}=0.045)$. To have a steady growing tsetse colony, it was important to make sure that the colony's daily mortality was kept below $1 \%$ and the fecundity $\mathrm{p} / \mathrm{f} 10$ was above 0.5 [29]. A major difference between field and laboratory-held flies is in the size of the blood meal taken; in our laboratory, flies held individually and fed on rabbits every third day take about $78 \%$ of the blood meal recorded for field flies. It is not surprising, then, that three feeds were sufficient only for a production rate of 0.70 pupae per cycle. The flies in Langley \& Stafford's [25] study were membrane-fed on defribinated pig blood, which results in an even lower meal size, lower survival rate, lower fecundity and smaller pupae than when flies are fed on rabbits [20]. Based on the laboratory results, therefore, we can only conclude that tsetse requires at least four or five laboratory-type meals per pregnancy cycle to reproduce satisfactorily, which cannot necessarily be taken to mean the same number of meals in the field.

Pupal quality as measured by weight and converted to size classes showed that the distribution of the pupae percentage in the different size classes produced by females G.pallidipes maintained under both feeding regime diets was found to be different in both feeding frequency. Pupae produced in under feeding frequency of three times per week fell mostly into the smaller size categories A-C compared with pupae maintained an under feeding frequency of five times per week which fell mostly into categories C-E but statistically significant variation were not recorded in all class except D class pupae. Furthermore, pupae quality decreases as the flies getting older and older. The highest percentage of pupal quality class (class D) ( 48\% was recorded in flies fed five times per week (48\% ) compare to other feeding regimes (35.9\%).This implies that flies fed five times per week gave the high quality of pupae than flies fed three times per week. However, five times feeding regime had a superior effect on the production of quality pupae than other feeding regime [33] found that the weight of a pupa depends on the amount of blood taken by a female during pregnancy, with a highly significant correlation between puparium weight and quality of blood feed. These results were confirmed by Jordan et al. who found that heavier pupae were produced by well-nourished females [34]. Similar results were reported by Langley and Pimley who found a weight of 26-28 $\mathrm{mg}$ from in vitro feeding [22]. Pupal quality is an indication of the nutritional status of the fly and is assessed in terms of pupal weight and size [35,36]. Puparial class is a good overall quality indicator of the effectiveness of colony maintenance; each weight class can be defined using a size-sorting machine. The mean pupal weights should approximate the values developed by Zegler and Russ, and no more than $10 \%$ of the puparium should be in weight class A [37].

\section{Conclusion}

Finally the study concluded that feeding frequency greatly affected both the productivity and survival rate of G.pallidpes reared under laboratory conditions. The survival and pupae production of G. pallidipes flies appeared to be governed mainly by their feeding frequency, and require at least four or five laboratory-type meals per pregnancy cycle to reproduce satisfactorily and five laboratorysized meals may be sufficient to meet the energy demands of normal larval development in the laboratory which increased their productivity compared to three-sized meal.

\section{Acknowledgement}

I would like to thank all participants on the preparation of this manuscript and my Institution, National Institute for Control and Eradication of Tsetse flies and Trypanosomosis.

\section{Availability of Data and Material}

Not applicable in this section however, all required Data will be available on request of correspondent Author.

\section{Consent for Publication}

not applicable

\section{Competing of Interests}

The authors have not declared any conflict (competing) of interests and not applicable.

\section{References}

1. Gooding R, Krafsur E (2005) Tsetse genetics: Contributions to biology, systematics, and control of tsetse flies. Annu Rev Entomo 50: 101-123.

2. Herder S, Simo G, Nkinin S, Njiokou F (2002) Identification of trypanosomes in wild animals from southern Cameroon using the polymerase chain reaction (PCR). Parasite 9: 345-349.

3. Langridge W (1976) A tsetse and trypanosomiasis survey of Ethiopia.

4. Moard (2004) Improving Productivity \& Market Success of Ethiopian Farmers.

5. Knipling E (1955) Possibilities of insect control or eradication through the use of sexually sterile males. Journal of Economic Entomology 48: 459-462.

6. Jaenson T, Takken W (1980) Rearing of Glossina pallidipes using membrane-feeding technology. Entomologia Experimentalis et Applicata 27: 102-104.

7. Vreysen M (2001) Principles of area-wide integrated tsetse fly control using the sterile insect technique. Médecine tropicale 61: 397-410.

8. Vreysen MJ, Saleh KM, Ali MY, Abdulla AM, Zhu ZR, et al. (2000) Glossina austeni (Diptera: Glossinidae) eradicated on the island of Unguja, Zanzibar, using the sterile insect technique. Journal of Economic Entomology 93: 123-135.

9. ABD-Alla A, Bossin H, Cousserans F, Parker A, Bergoin M, et al. (2007) Development of a non-destructive PCR method for detection of the salivary gland hypertrophy virus (SGHV) in tsetse flies. Journal of virological methods 139: 143-149. 
10. ABD-Alla AM, Cousserans F, Parker AG, Jehle JA, Parker NJ, et al. (2008) Genome analysis of a Glossina pallidipes salivary gland hypertrophy virus reveals a novel, large, double-stranded circular DNA virus. J Virol 82: 4595-4611.

11. ABD-Alla AM, Kariithi HM, Parker AG, Robinson AS, Kiflo MM, et al. (2010) Dynamics of the salivary gland hypertrophy virus in laboratory colonies of Glossina pallidipes (Diptera: Glossinidae). Virus research: 150: 103-110.

12. Kebede A (2012) Assessment of Survival and Reproductive Performance of Glossina Pallidipes Maintained Under Blood of Different Animals at Kality Tsetse Rearing and Irradiation Center. Addis Ababauniversity.

13. Knipling E (1955) Possibilities of insect control or eradication through the use of sexually sterile males. Journal of Economic Entomology 48: 459-462.

14. Feldmann U, Ochieng'-Odero J (1994) Guidelines for the rearing of tsetse flies using the membrane feeding technique.

15. (2000) IAEA Development of cost-effective diets for use in mass production of tsetse flies. Vienna:

16. Feldmann U, Luger D, Barnor H, Dengwat L, Ajagbonna B, et al. (1992) Tsetse fly mass rearing: Colony management, deployment of sterile flies, related research and development.

17. Gooding RH, Feldmann U, Robinson AS (1997) Care and maintain of tsetse colonies. In: Crampton, JM, Beard CB and Louis C (Eds.), molecular biology of insect disease vectors and methods manual. Chapman and Hall, London, UK, pp. 41-55.

18. Opiyo E, Luger D, Robinson AS (2000) New systems for the large scale production of male tsetse flies (Diptera: Glossinidae). In: Tan KH (Eds.) Proceedings: Area-Wide Control of fruit flies and other insect pests and the $5^{\text {th }}$ international Symposium on Fruit flies of Economic importance, 28 May-5 June, Penang, Malaysia. Penerbit University Sains Malaysia, Pulau Pinang, Malaysia, pp. 337-344.

19. (2006) FAO/ IAEA. Standard operating procedures for mass rearing tsetse flies, IAEA, Vienna, Austria.

20. Langley P, Pimley R (1975) Quantitative aspects of reproduction and larval nutrition in Glossina morsitans morsitans Westw.(Diptera, Glossinidae) fed in vitro. Bulletin of Entomological Research 65: 129-14.

21. Langley P, Pimley R (1979) Storage and mobilisation of nutriment for uterine milk synthesis by Glossina morsitans. Journal of Insect Physiology 25: 193-197.

ISSN: 2574-1241

DOI: $10.26717 /$ BJSTR.2020.28.004604

Behablom Meharenet. Biomed J Sci \& Tech Res

This work is licensed under Creative

Commons Attribution 4.0 License

Submission Link: https://biomedres.us/submit-manuscript.php
22. Hamilton LC (2012) Statistics with Stata: version 12. Cengage Learning

23. Boyle J (1971) Effect of blood intake of Glossina austeni Newst. on pupal weights in successive reproductive cycles. Bulletin of Entomological Research 61: 1-5

24. Langley P, Stafford K (1990) Feeding frequency in relation to reproduction in Glossina morsitans morsitans and $G$. pallidipes. Physiological entomology 15: 415-421.

25. Mellanby H (1937) Experimental work on reproduction in the tsetse fly, Glossina palpalis. Parasitology 29: 131-141.

26. Nash T, Jordan A, Boyle J (1967) A method of maintaining Glossina austeni Newst. singly, and a study of the feeding habits of the female in relation to larviposition and pupal weight. Bulletin of Entomological Research 57: 327-336.

27. Randolph Se, Rogers Dj, Kiilu J (1990) Rapid changes in the reproductive cycle of wild-caught tsetse, Glossina pallidipes Austen, when brought into the laboratory. International Journal of Tropical Insect Science 11: 347-354.

28. (2012a) IAEA Improved and Harmonized Quality Control for Expanded Tsetse Production, Sterilization and Field Application.

29. Jordan AM (1986) Trypanosomiasis control and African rural development, Longman London; New York.

30. Mews A, Langley P, Pimley R, Flood M (1977) Large-scale rearing of tsetse flies (Glossina spp.) in the absence of a living host. Bulletin of Entomological Research 67: 119-128.

31. Moloo S (1976) Aspects of the nutrition of adult female Glossina morsitans during pregnancy. Journal of Insect Physiology 22: 563-567.

32. Kettle DS (1984) Medical and veterinary entomology, Croom Helm Ltd.

33. Jordan A, Nash T, Boyle J (1967) The rearing of Glossina austeni Newst. with lop-eared rabbits as hosts: I.-Efficacy of the method. Annals of Tropical Medicine \& Parasitology 61: 182-188.

34. Jordan A, Langley P (1991) The tsetse research laboratory. Annals of Tropical Medicine \& Parasitology 85: 11-20.

35. (2012b) IAEA Quality Control for Expanded Tsetse Production, Sterilization and Field Application.

36. Zelger R, Russ K (1976) Puppentrennmaschine mit zwei Walzenpaaren. Z Angew Zool 63: 257.

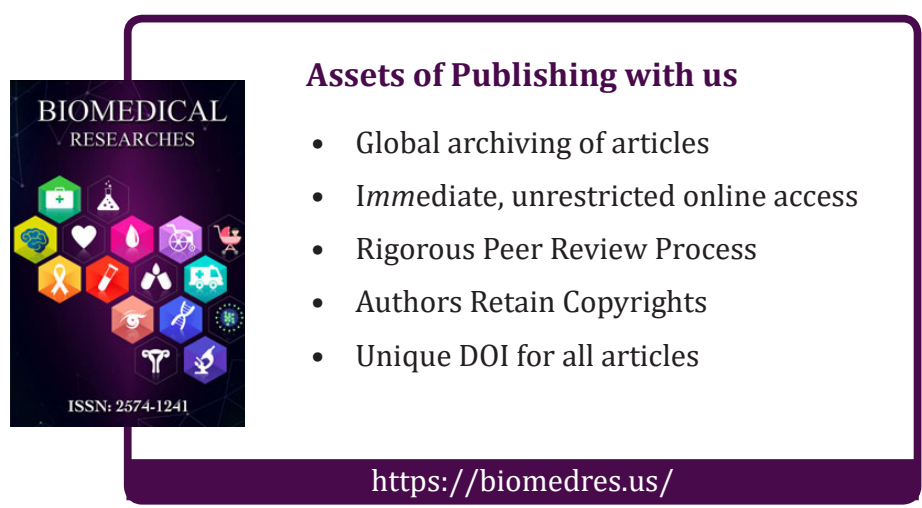

